\title{
Factors influencing pre-natal fertility in the brown marsupial mouse, Antechinus stuartii
}

\author{
Lynne Selwood \\ Department of Zoology, La Trobe University, Plenty Road, Bundoora, Victoria 3083, Australia
}

\begin{abstract}
Summary. The number of eggs ovulated per ovary, estimated as the number of corpora lutea in histological sections, was $6.1 \pm 1.4$ (s.d.) in 100 sides of the reproductive tract in 53 female Antechinus stuartii during 5 breeding seasons. Post-ovulatory fertility, estimated as the number of normal embryos divided by the number of corpora lutea, was $74 \pm 25 \%$ (s.d.). By analysis of variance the number of corpora lutea per ovary did not vary significantly with the year of breeding or the origin of the female but did decline significantly $(P<0.05)$ with increasing age of the female to $5.4 \pm 1 \cdot 1$ (s.d.) in females in their second breeding season. Analysis of variance showed that the mean percentage of surviving embryos did not vary significantly with the year of breeding, origin or age of the female, the stage of development or whether the female had been mated 1, 2 or 3 times. Failure of development was most marked during fertilization and cleavage to the unilaminar blastocyst and only $79 \pm 21 \%$ (s.d.) of embryos reached the latter stage. Additional mortality occurred mainly during implantation.
\end{abstract}

\section{Introduction}

The dasyurid marsupial Antechinus stuartii is monoestrous (Marlow, 1961; Woolley, 1966a), ovulates spontaneously (Woolley, 1966a) and has an unusual life history characterized by a highly synchronized breeding season of about 2 weeks (Wood, 1970; Selwood, 1982), which is followed by mortality of all males in the field (Woolley, 1966a; Wood, 1970) or mortality or senility of males in the laboratory (Woolley, 1966a). A variable but usually small percentage of females survives to breed in a 2nd year (Woolley, 1966a; Wood, 1970). The gestation length is 27 days (Selwood, 1980, 1981) and the number of pouch young is the same or one less than the number of teats in the pouch (Woolley, 1966a; Wood, 1970), which vary from 6 to 10 depending on the geographical locality (Woolley, 1966a).

The rate and timing of pre-natal embryonic mortality in polytocous marsupials has been investigated in a few species (Hill, 1910; Hughes, Thomson \& Owen, 1965; Lyne \& Hollis, 1977), but only in the opossum, Didelphis virginiana (Hartman, 1916, 1919), has this information been collected for the entire period of embryonic development. No information is available on agespecific intrauterine fertility in polytocous marsupials or on the influence of multiple matings or length of sperm storage on fertility. This study analyses the possible relationships between pre-natal fertility in $A$. stuartii and a number of factors, including age or parity of the female, geographical location, teat number, year of breeding, stage of embryonic development, length of sperm storage and number of matings. 


\section{Materials and Methods}

Brown marsupial mice (Antechinus stuartii) were trapped in two wet scherophyll forest areas, Kinglake and Warburton, near Melbourne, and from two mountainous wet scherophyll forests on Lake Mountain and Mount Donna Buang during July to September in 1975, 1976, 1977, 1978 and 1981. After collection each female was examined to determine the teat number, whether she was in her first or second breeding season, on the basis of her weight and pouch characteristics (Woolley, 1966a), and, if she was pregnant, to determine the approximate stage of pregnancy. The animals were maintained in cages with detachable nest boxes, designed for this species (Woolley, 1973). They were fed on live insects, meat and dried cat food, with water provided ad libitum (Selwood, 1982).

Females in oestrus, detectable by the presence of large numbers of cornified epithelial cells in the urine (Godfrey, 1969; Selwood, 1980), were mated with males from the colony. Mating was confirmed if penetration was observed or if spermatozoa were found in the urine of the female. Each female was mated 1 to 4 times. Urine samples from each female were monitored daily to detect the marked decrease in number of epithelial cells in the urine which usually occurs within $24 \mathrm{~h}$ of ovulation in this species (Selwood, 1980). In females that have recently mated, the disappearance of spermatozoa from the urine is also an indication that ovulation has occurred (Selwood, 1980, 1982). The maximum and minimum duration of storage of spermatozoa was measured in days from the day of the first confirmed mating or the day of the last confirmed mating, respectively, to the estimated date of ovulation.

Ovaries and uteri were removed from females at daily intervals during the 27-day gestation period after anaesthesia with ether, if both sides of the reproductive tract were to be removed, or with sodium amytal if the excisions were unilateral. In the latter case, the uterine neck and ovarian blood vessels were ligated before removal of the right ovary and uterus.

For each ovary, the number of corpora lutea were counted, then ovaries were fixed in Bouin's fluid for $24 \mathrm{~h}$, dehydrated, embedded in paraffin wax, sectioned at $8 \mu \mathrm{m}$ and stained in haematoxylin and eosin; the numbers of corpora lutea were re-counted in the sections. Identification of corpora lutea was based on the study by Woolley (1966b) of the corpora lutea of pregnancy of $A$. stuartii, and corpora lutea were identified as post-ovulatory follicles, which had shed the ovum and in which the granulosa cells showed various degrees of luteinization dependent on the stage of pregnancy. Corpora lutea of pregnancy can be readily distinguished from the luteinized follicles which occur infrequently in $A$. stuartii by the retention of an apparently normal ovum in follicles which then luteinize (Woolley, 1966b).

When tubal eggs were obtained, the oviducts were processed with the ovaries and the number of eggs counted in the sections. Eggs which had passed the ampulla of the oviduct where fertilization occurs in this species (Selwood, 1982) and which had no spermatozoa inside the zona pellucida were scored as unfertilized eggs. Eggs which contained more than one spermatozoon were recorded as polyspermic, a condition which has been shown to occur in this animal (Selwood, 1982) and Dasyurus viverrinus (Hill, 1910).

Each uterus was slit along the inner margin and the embryos were everted into phosphatebuffered saline and the numbers of normal and non-viable embryos were counted. Unfertilized uterine eggs were detected by the absence of the marked polarization of the yolky cytoplasm which follows fertilization in this animal (Selwood, 1982) and by the absence of spermatozoa in the outer egg coats. During cleavage, eggs which had no spermatozoa detectable in the outer egg coats and which were unevenly fragmented into cytoplasmic masses of variable shape and size were scored as unfertilized because of their similarity to the unfertilized eggs described by Hill (1910) in $D$. viverrinus and Hartman $(1916,1919)$ in D. virginiana. Embryos with apparently normal morphology but which were retarded by more than one cleavage division compared with the other uterine eggs were scored as abnormal. Blastocysts that were much smaller or collapsed and implanted embryos that were grossly retarded or with abnormal morphology were scored as abnormal. The normal 
embryos were classified according to the timetable of development outlined for this species (Selwood, 1980, 1981): (1) tubal eggs and cleavage to the unilaminar blastocyst of 32 cells; (2) the expansion of the unilaminar blastocyst: (3) the formation of the germ layers; and (4) the implanted fetus until just before birth. The percentage of surviving embryos was calculated as the number of normal embryos divided by the number of eggs ovulated (which was taken to be equal to the number of corpora lutea) multiplied by 100 .

Specimens were grouped according to the following categories: 1, year of sampling; 2 , locality where females were trapped; 3 , age of females; 4 , laboratory-mated versus pregnant when trapped; and 5 , intact females versus females from which the right ovary, oviduct and uterus had been removed. Analysis of variance was used to compare groups in each category using the variables (a) number of corpora lutea per ovary and (b) the percentage of surviving embryos per side of the reproductive tract. In addition, the same technique was used to compare the percentage of surviving embryos per side of the reproductive tract for two additional categories; 6 , stage of development and 7 , the number of times the female was successfully mated. To examine the possibility that the first copulation contributed the spermatozoa for fertilization, the correlation coefficients between the percentage of surviving embryos and the length of sperm storage from the first confirmed mating to ovulation and from the last confirmed mating to ovulation were calculated. When appropriate, $t$ tests were also used. All values are given as mean \pm s.d. The mean differences between groups were considered to be statistically significant if the appropriate test gave a $P$ value of $<0.05$.

\section{Results}

For 100 specimens during the 5 years of sampling the mean \pm s.d. number of corpora lutea per ovary was $6.1 \pm 1.4$ and the mean \pm s.d. percentage of surviving embryos was $74 \pm 25 \%$. From year to year, analysis of variance showed no significant difference in the number of corpora lutea per ovary or in the percentage of surviving embryos (Table 1). The number of embryos was one

Table 1. The number of corpora lutea per ovary and the percentage of surviving embryos per uterus for A. stuartii during 5 years of breeding, in different localities and in the 1 st and 2 nd breeding seasons

\begin{tabular}{|c|c|c|c|c|c|}
\hline & & \multicolumn{2}{|c|}{ No. of: } & \multirow[b]{2}{*}{ Corpora lutea } & \multirow[b]{2}{*}{$\%$ surviving embryos } \\
\hline & & Animals & Specimens & & \\
\hline Year & $\begin{array}{l}1975 \\
1976 \\
1977 \\
1978 \\
1981\end{array}$ & $\begin{array}{r}11 \\
7 \\
4 \\
25 \\
6\end{array}$ & $\begin{array}{r}22 \\
12 \\
7 \\
47 \\
12\end{array}$ & $\begin{aligned} 6.6 \pm 1.2 \\
6.3 \pm 1.9 \\
5.6 \pm 1.0 \\
5.9 \pm 1.4 \\
6.2 \pm 1.2 \\
\mathrm{~F}=1.165, P>0.3\end{aligned}$ & $\begin{array}{c}71 \pm 25 \\
71 \pm 19 \\
91 \pm 12 \\
73 \pm 29 \\
78 \pm 15 \\
\mathrm{~F}=1.050, P>0.3\end{array}$ \\
\hline Origin & $\begin{array}{l}\text { Kinglake } \\
\text { Warburton } \\
\text { Lake Mountain } \\
\text { Donna Buang }\end{array}$ & $\begin{array}{r}4 \\
30 \\
14 \\
5\end{array}$ & $\begin{array}{r}7 \\
57 \\
26 \\
10\end{array}$ & $\begin{aligned} 6.7 \pm 1.3 \\
6.0 \pm 1.4 \\
6.1 \pm 1.5 \\
6.4 \pm 1.3 \\
F=0.822, P>0.4\end{aligned}$ & $\begin{array}{c}71 \pm 33 \\
73 \pm 26 \\
77 \pm 24 \\
80 \pm 15 \\
\mathrm{~F}=0.381, P>0 \cdot 7\end{array}$ \\
\hline Age & $\begin{array}{l}\text { First breeding season } \\
\text { Second breeding season }\end{array}$ & $\begin{array}{r}20 \\
9\end{array}$ & $\begin{array}{l}37 \\
18\end{array}$ & $\begin{aligned} & 6.2 \pm 1.6 \\
& 5.4 \pm 1.1 \\
& t= 2.17, P<0.04\end{aligned}$ & $\begin{array}{c}73 \pm 24 \\
73 \pm 31 \\
t=0.01, P>0.9\end{array}$ \\
\hline
\end{tabular}


more than the number of corpora lutea in 3 animals and 2 more in 1 animal. The percentage of surviving embryos was scored as $100 \%$ for these animals, in all of which all the embryos appeared normal. Embryonic development had proceeded to the 4-cell stage and expanding unilaminar blastocyst in 3 animals and to the bilaminar blastocyst with embryonic area in the other animal.

When animals from the 4 localities were compared, analysis of variance showed no significant differences in the number of corpora lutea per ovary or in the percentage of surviving embryos (Table 1). Information about the number of teats per pouch was not obtained for 16 animals, but for the remainder the teat numbers were 8 for the Donna Buang and Kinglake areas, mainly 8 with an occasional 9 for the Warburton area, and mainly 9 with an occasional 8 or 10 for the Lake Mountain area.

The mean number of corpora lutea per ovary in females in their first breeding season was significantly higher than that in females in their second breeding season (Table 1) but no significant difference was found between the mean percentage of surviving embryos for these two groups. As both pouch development and an increase in weight occur in pregnancy (Woolley, 1966a), it is difficult to assess accurately the reproductive status of pregnant animals so the comparisons made here between females in their first and second breeding season were on females which were not pregnant when trapped. They came mainly from the Warburton area and about one third of the females were parous (Table 1).

The mean \pm s.d. number of corpora lutea per ovary was $5.8 \pm 1.4$ in females which had been mated in the laboratory $(\mathrm{N}=56)$ and this was significantly lower $(t=2.14 ; 0.02<P<0.05)$ than the value of $6.4 \pm 1.3$ for females that were pregnant when trapped $(\mathrm{N}=44)$. The mean \pm s.d. percentage of surviving embryos was $74 \pm 24 \%$ for animals mated in the laboratory $(\mathrm{N}=56)$ and $75 \pm 24 \%$ for animals that were pregnant when trapped $(\mathrm{N}=44)(t=0.21$; $0.8<P<0.9)$. The percentage of surviving embryos in one uterus before laparotomy was $77 \pm 22 \%$ s.d. $(\mathrm{N}=83)$ and this was not significantly different from that of $62 \pm 34 \%$ s.d. $(\mathrm{N}=17)(t=1 \cdot 69 ; 0 \cdot 1<P<0 \cdot 2)$ for embryos in one uterus after laparotomy.

Analysis of variance showed that the mean percentage of surviving embryos was not significantly different in females that had been mated successfully 1,2 or 3 times (Table 2). Only one female was mated 4 times and $83 \%$ of her embryos had survived to the 4 -cell stage. The correlation coefficient was $-0 \cdot 16(P>0 \cdot 1)$ for the mean percentage of surviving embryos and the length of sperm storage in days from the first confirmed mating to ovulation and $-0 \cdot 10(P>0 \cdot 2)$ for the mean percentage of surviving embryos and the length of sperm storage in days from the last confirmed mating to ovulation. The interval between the first confirmed mating and ovulation ranged from 7 to 21 days and between the last confirmed mating and ovulation from 2 to 11 days.

The mean percentages of surviving embryos at each stage of development are recorded in Table 3. The first and greatest mortality of around $20 \%$ of embryos was found in the first 6 days of development during fertilization and cleavage to the unilaminar blastocyst. Unfertilized eggs and retarded early cleavage stages were found in the uterus at this stage and throughout most of

Table 2. The percentage (mean \pm s.d.) of surviving embryos in A. stuartii that had been mated a number of times

\begin{tabular}{|c|c|c|c|c|}
\hline \multicolumn{2}{|c|}{ Mating occurrence: } & \multirow{2}{*}{\multicolumn{2}{|c|}{ No. of: }} & \multirow[b]{3}{*}{$\%$ surviving embryos* } \\
\hline \multirow[b]{2}{*}{ No. confirmed } & \multirow{2}{*}{$\begin{array}{l}\text { Days before } \\
\text { ovulation }\end{array}$} & & & \\
\hline & & Animals & Specimens & \\
\hline 1 & $7-9$ & 9 & 18 & $82 \pm 15$ \\
\hline 2 & $2-16$ & 10 & 19 & $63 \pm 34$ \\
\hline 3 & $2-21$ & 9 & 17 & $82 \pm 19$ \\
\hline
\end{tabular}

${ }^{*} \mathrm{~F}=2 \cdot 649, P>0 \cdot 05$. 
Table 3. The percentage (mean \pm s.d.) of surviving embryos per uterus at different stages of embryonic development in A. stuartii

\begin{tabular}{lcccc}
\hline & \multirow{2}{*}{$\begin{array}{c}\text { Duration* } \\
\text { of stage } \\
\text { Stage of development }\end{array}$} & \multicolumn{2}{c}{ No. of: } & \\
\cline { 5 - 5 } & (days) & Animals & Specimens & \% surviving embryos $\dagger$ \\
\hline (1) Tubal egg-32-cell blastocyst & $0-6$ & 13 & 26 & $79 \pm 21$ \\
(2) Expanded unilaminar & $7-15$ & 14 & 25 & $77 \pm 27$ \\
$\begin{array}{l}\text { blastocyst-1-5 mm blastocyst } \\
\text { (3) Bilaminar blastocyst-advanced }\end{array}$ & $16-22$ & 16 & 32 & $77 \pm 21$ \\
primitive streak & $23-27$ & 10 & 17 & $60 \pm 28$ \\
\hline
\end{tabular}

* Selwood $(1980,1981)$.
$\dagger \mathrm{F}=2 \cdot 448, P>0 \cdot 06$.

pregnancy. Abnormal embryos were rarely found during expansion of the unilaminar blastocyst and formation of the germ layers, so that during these stages the percentage of surviving embryos was mainly a result of mortality during stage 1 and did not markedly decline. Additional mortality of about $13 \%$ of embryos occurred during implantation (Table 3) and abnormal implanted embryos were found in the uterus in the last 5 days of pregnancy. By analysis of variance, the percentage of surviving embryos did not vary significantly with the stage of development (Table 3 ). However, a $t$ test showed that the percentage of surviving embryos of stage 4 was significantly different ( $t=2 \cdot 20 ; 0.02<P<0.05$ ) from that of the preceding stage, presumably because of the additional mortality which occurred during implantation.

\section{Discussion}

Since brown marsupial mice produce a mean of $6 \cdot 1$ corpora lutea per ovary, each animal would ovulate about 12 eggs of which $74 \%(=9)$ would survive to become potential pouch young. This means that for animals in the geographical areas where the teat number was 8 or mainly 9 , in the case of Lake Mountain, the mean number of young born would be slightly in excess of or equal to the number of teats. Pre-natal losses therefore account for a mean of $26 \%$ of the eggs ovulated and post-natal mortality during transfer to the pouch to a further mean loss of $8 \%$, assuming that every teat in the pouch is occupied. In areas where the teat number is 9 post-natal mortality during transfer to the pouch is about $4 \%$. If high mortality is not a feature of the journey to the pouch then all or nearly all the teats of the pouch should be occupied. This in fact occurs in all populations of $A$. stuartii for which field studies of litter size have been made (Woolley, 1966a; Wood, 1970).

The lack of significant variation in the number of corpora lutea per ovary and in the embryonic survival ratio from year to year during the 5 years and from area to area suggest that the number of potential pouch young produced by each animal does not vary with the year of breeding or the locality in which the animal was trapped. A similar lack of annual variation based on a study of litter size was demonstrated by Wood (1970) for a population of these marsupial mice at Mt Glorious in Queensland. Unfortunately, in some years and for some areas, the sample size was rather small (Table 1) and larger samples could show significant variation where none has been demonstrated in this stidy.

While this study did not include animals from areas where the teat numbers were mainly 6,7 or 10 the mean \pm s.d. number of eggs ovulated per ovary is $7 \cdot 3 \pm 1 \cdot 5(\mathrm{~N}=16)$ in an area about 450 $\mathrm{km}$ north east of Melbourne where the teat number is 10 and the percentage of surviving embryos to the large blastocyst stage is $92 \%$ (calculated from Appendices 5, 6, $7 \& 15$ of Woolley, 1966b). In these specimens embryonic mortality was confined to the blastocyst stage and if no further mortality occurred during later development the mean number of potential pouch young would be 
$13 \cdot 4(92 \%$ of $14 \cdot 6)$. A comparison between this and Woolley's (1966b) study suggests that the number of eggs ovulated and the percentage of embryos that survive can vary between distant populations so that the mean number of potential pouch young is slightly in excess of the number of teats in the pouch.

Retention of fertilizing capacity during long-term storage of spermatozoa has been reported for a number of eutherian species (Thibault, 1973; Gwatkin, 1977), including vespertilionid bats (Racey \& Potts, 1970; Racey, Suzuki \& Medway, 1975), the llama (Thibault, 1973), hares (Martinet \& Raynaud, 1975), and mice (Ullmann, 1976). In many marsupials, oestrus is short and spermatozoa are stored for only a day or so (Hartman, 1916, 1919, 1923; Godfrey, 1969, 1975; Lyne \& Hollis, 1977), but in some dasyurids, in which oestrus is longer, relatively long periods of storage of spermatozoa have been demonstrated. Motile spermatozoa have been found 2 weeks after oestrus in D. viverrinus (Hill \& O'Donoghue, 1913) and 5 days after copulation in $A$. stuartii (Woolley, 1966b). Fertilized embryos of $A$. stuartii were obtained 7-9 days after a single copulation in this study (Table 2). It is not known how many times brown marsupial mice mate in the field, but as animals copulate readily during oestrus, especially towards the end of oestrus in the laboratory, presumably multiple matings do occur on occasion in the field. However, as the percentage of surviving embryos does not vary significantly with the number of confirmed matings in the laboratory, animals do not seem to have a particular advantage if there are multiple matings. There is some suggestion that the biggest males mate first in the field and exclusively occupy the females before dying (Braithwaite, 1979). This implies that the first male to mate with a female provides the spermatozoa for fertilization. This study cannot confirm or deny this but does suggest, from a comparison of correlation coefficients, that if the spermatozoa stored in the isthmus from the first mating are the fertilizing spermatozoa then the fertilizing capacity of these gametes does not decline over 21 days.

While females in their second breeding season ovulated significantly fewer eggs than females in their first season (Table 3), the maintenance of a similar percentage of embryonic survival meant that older females produce sufficient potential pouch young to fill or almost fill the pouch $(73 \%$ of $10 \cdot 8=8$ potential pouch young). A reduction in fecundity with age due mainly to declining egg quality and uterine failure has been demonstrated in women, and some laboratory eutherian animals (see reviews by Biggers, 1969; Adams, 1970, 1975; Jones, 1970; Finn, 1970). In addition, in some eutherian species the number of eggs ovulated declines towards the end of the reproductive phase (Adams, 1970, 1975).

In marsupials, partly because placental scars do not form, information of age-specific fertility is confined to comparisons of litter size in polytocous species (Wood, 1970; Morton, 1978; Begg, 1981) and the presence or absence of pouch young in monotocous species (Sharman, 1970; Martin, 1981) and very little information is available for the effect of age on intrauterine fertility. It has been demonstrated that fertility declines with generation time in some species of laboratory-reared marsupials but this is usually associated with sterility associated with follicular atresia in the Virginian opossum (Hartman, 1923), and Marmosa robinsoni (Godfrey, 1975), with failure to rear litters in Sminthopsis larapinta (Godfrey, 1969) and Marmosa mitis (Barnes \& Wolf, 1971) or with a possible nutritional deficiency (Godfrey \& Crowcroft, 1971). Reproductive success declines with age or parity in the Virginian opossum due to decreased fertility, reduced litter sizes and decreased ability to rear young (Reynolds, 1952; Barnes, 1968; Jurgelski \& Porter, 1974). A decline in the number of eggs ovulated with age as was found in $A$. stuartii in this study has not been reported in other polytocous marsupials but would be difficult to detect without counting the number of corpora lutea during pregnancy. As the number of eggs ovulated in polytocous marsupials is usually greatly in excess of the number of teats and the litter number is never higher than the number of teats, any decline in prenatal fertility would not be detectable until the number of potential pouch young is less than the number of teats. In most cases, therefore, an examination of litter size gives little information about prenatal mortality.

The slight reduction in the mean number of eggs ovulated per ovary in females which were 
mated in the laboratory might be due to the relatively high proportion (about $31 \%$, Table 3) of females in their second breeding season compared to field conditions where only about $15 \%$ of breeding females are in their second season (Woolley, 1966a). Nutritional factors may also be important but are less likely to influence numbers of corpora lutea as animals were trapped about 1 month before the onset of oestrus.

A high rate of failure in development during fertilization and cleavage has been reported in a number of polytocous marsupials including D. virginiana (Hartman, 1919), D. viverrinus (Hill, 1910), Sarcophilus harrisii (Hughes, 1982), and Perameles nasuta and Isoodon macrourus (Lyne \& Hollis, 1977) as well as in $\boldsymbol{A}$. stuartii (Selwood, 1980) although the actual rate varies from species to species. Failure of fertilization appears to be especially high in those marsupial species that ovulate a large number of eggs, i.e. D. virginiana, D. viverrinus and $S$. harrisii. This contrasts markedly with the situation in many polytocous eutherians in which fertilization is relatively efficient (McLaren, 1974; Hafez \& Jainudeen, 1974). Failure to develop during early development and during early implantation, such as was found in $A$. stuartii in this study, has also been reported for a number of eutherians (McLaren, 1974; Hafez \& Jainudeen, 1974). Prenatal mortality appears to vary within the genus Antechinus and species $A$. stuartii, such that in one population of $A$. stuartii mortality occurred during the blastocyst stages (Woolley, 1966b), whereas mortality was confined mainly to fertilization, early cleavage and implantation in this study and during advanced pregnancy in $\boldsymbol{A}$. bellus and $A$. bilani (Calaby \& Taylor, 1981).

This study of pre-natal fertility in $A$. stuartii has demonstrated some features of its reproduction which were not apparent from previous studies of litter size of pouch young. Pre-natal fertility declined with age in the female due to a reduction in the number of eggs ovulated, but the decline was not sufficient to affect markedly the number of pouch young. While the mean number of eggs ovulated was usually well in excess of the number of available teats in the pouch, the greatest mortality occurred during pre-natal development not during the post-natal migration to the pouch and location of an unoccupied teat. Its maintenance of a high reproductive potential in the laboratory and its tolerance to surgical intervention during pregnancy make this animal very suited to further embryological studies.

The animals in this study were trapped under permits by the Fisheries and Wildlife Division of the Ministry for Conservation in Victoria and the co-operation of the Division is gratefully acknowledged. Some specimens were obtained from the Wallaby Creek catchment Area at Kinglake due to the generosity of the Melbourne and Metropolitan Board of Works, who permitted trapping in that area. Many friends kindly assisted with the trapping. Dr P. Woolley and her staff gave much helpful advice and Mr A. Donnelly and Mrs I. Douglas gave valuable technical assistance. I also thank Dr T. Selwood for statistical advice and analysis of data on the Burroughs 6700 Computer at Monash University, Clayton, Victoria.

\section{References}

Adams, C.E. (1970) Ageing and reproduction in the female mammal with particular reference to the rabbit. J. Reprod. Fert., Suppl. 12, 1-16.

Adams, C.E. (1975) Effects of maternal age on ovulation, fertilization and embryonic development. In Aging Gametes, pp. 231-248. Ed. R. J. Blandau. Karger, Basel.

Barnes, R.D. (1968) Small marsupials as experimental animals. Lab. Anim. Care 18, 251-257.

Barnes, R.D. \& Wolf, H.G. (1971) The husbandry of Marmosa mitis as a laboratory animal. Int. Zoo Yb. 11. 50-54.

Begg, R.J. (1981) The small mammals of Little Nourlangie Rock, N.T.2. Ecology of Antechinus bilarni, the sandstone antechinus (Marsupialia: Dasyuridae). Aust. Wild. Res. 8, 57-72.

Biggers, J.D. (1969) Problems concerning the uterine causes of embryonic death, with special reference to the effects of ageing of the uterus. J. Reprod. Fert., Suppl. 8, 27-43.

Braithwaite, R.W. (1979) Social dominance and habitat utilization in Antechinus stuartii (Marsupialia). Aust. J. Zool. 27, 517-528.

Calaby, J.H. \& Taylor, J.M. (1981) Reproduction in two marsupial mice, Antechinus bellus and A. bilarni (Dasyuridae), of tropical Australia. J. Mammal. 62, 329-34l.

Finn, C.A. (1970) The ageing uterus and its influence on 
reproductive capacity. J. Reprod. Fert, Suppl. 12, 3138.

Godfrey, G.K. (1969) Reproduction in a laboratory colony of the marsupial mouse Sminthopsis larapinta (Marsupialia: Dasyuridae). Aust. J. Zool. 17, 637654.

Godfrey, G.K. (1975) A study of oestrus and fecundity in a laboratory colony of mouse opossums (Marmosa robinsoni). J. Zool., Lond. 175, 541-555.

Godfrey, G.K. \& Crowcroft, P. (1971) Breeding the fattailed marsupial mouse Sminthopsis crassicaudata in captivity. Int. Zoo Yb. 11, 33-38.

Gwatkin, R.B.L. (1977) Fertilization Mechanisms in Man and Mammals, pp. 27-32. Plenum Press, New York.

Hafez, E.S.E. \& Jainudeen, M.R. (1974) Reproductive failure in females. In Reproduction in Farm Animals pp. 351-372. Ed. E. S. E. Hafez. Lea and Febiger, Philadelphia.

Hartman, C.G. (1916) Studies in the development of the opossum Didelphys virginiana L. I. History of the early cleavage. II. Formation of the blastocyst. J. Morph. 27, 1-84.

Hartman, C.G. (1919) Studies in the development of the opossum Didelphys virginiana L. III. Description of new material on maturation, cleavage and entoderm formation. IV. The bilaminar blastocyst. J. Morph. 32, $1-144$.

Hartman, C.G. (1923) The oestrous cycle of the opossum. Am. J. Anat. 32, 353-421.

Hill, J.P. (1910) The early development of the Marsupialia, with special reference to the native cat Dasyurus viverrinus. $Q$. Jl microsc. Sci. 56, 1-134.

Hill, J.P. \& O'Donoghue, C.H. (1913) The reproductive cycle in the marsupial Dasyurus viverrinus. $Q . J l$ microsc. Sci. 59, 133-174.

Hughes, R.L. (1982) Reproduction in the Tasmanian Devil Sarcophilus harrisii (Dasyuridae, Marsupialia). In Carnivorous Marsupials, pp. 49-63. Ed. M. Archer. Roy. Zool. Soc. N.S.W., Sydney.

Hughes, R.L., Thomson, J.A. \& Owen, W.H. (1965) Reproduction in natural populations of the Australian ringtail possum, Pseudochierus perigrinus (Marsupialia: Phalangeridae) in Victoria. Aust. J. Zool. 13, 383-406.

Jones, E.C. (1970) The ageing ovary and its influence on reproductive capacity. J. Reprod. Fert., Suppl. 12, 17 . 30 .

Jurgelski, W., Jr \& Porter, M.E. (1974) The opossum (Didelphis virginiana Kerr) as a biomedical model. III. Breeding the opossum in captivity: methods. Lab. Anim. Sci. 24, 412-426.

Lyne A.G. \& Hollis, D.E. (1977) The early development of marsupials, with special reference to bandicoots. In Reproduction and Evolution pp. 293-302. Eds J. H. Calaby \& C. H. Tyndale-Biscoe. Aust. Acad. Sci., Canberra.

Marlow, B.J. (1961) Reproductive behaviour in the marsupial mouse, Antechinus flavipes (Waterhouse) and the development of the pouch young. Aust. $J$. Zool. 9, 203-218.

Martin, R.W. (1981) Age-specific fertility in three populations of the koala Phascolarctos cinereus Goldfuss, in Victoria. Aust. Wildl. Res. 8, 275-283.

Martinet, L. \& Raynaud, F. (1975) Prolonged spermatozoan survival in the female hare uterus: explanation of superfetation. In Biology of Spermatozoa, pp. 134 144. Eds E. S. E. Hafez \& C. G. Thibault. Karger, Basel.

McLaren, A. (1974) Fertilization, cleavage and implantation. In Reproduction in Farm Animals, pp. 143-165. Ed. E. S. E. Hafez. Lea and Febiger, Philadelphia.

Morton, S.R. (1978) An ecological study of Sminthopsis crassicaudata (Marsupialia: Dasyuridae). III. Reproduction and life history. Aust. Wildl. Res, 5, 183-212.

Racey, P.A. \& Potts, D.M. (1970) The relationship between stored spermatozoa and the uterine epithelium in the pipistrelle bat (Pipistrellus pipistrellus). $J$. Reprod. Fert. 22, 57-63.

Racey, P.A., Suzuki, F. \& Medway, Lord (1975) The relationship between stored spermatozoa and the oviducal epithelium in bats of the genus Tylonycteris. In The Biology of Spermatozoa, pp. 123-133. Eds E. S. E. Hafez \& C. G. Thibault. Karger, Basel.

Reynolds, H.C. (1952) Studies on reproduction in the opossum (Didelphis virginiana virginiana). Univ. Calif. Publs. Zool. 52, 223-284.

Selwood, L. (1980) A timetable of embryonic development of the dasyurid marsupial Antechinus stuartii (Macleay). Aust. J. Zool. 28, 649-668.

Selwood, L. (1981) Delayed embryonic development in the dasyurid marsupial, Antechinus stuartii. J. Reprod. Fert., Suppl. 29, 79-82.

Selwood, L. (1982) A review of maturation and fertilization in marsupials with special reference to the dasyurid Antechinus stuartii. In Carnivorous Marsupials, pp. 65-76. Ed. M. Archer. Roy. Zool. Soc. N.S.W., Sydney.

Sharman, G.B. (1970) The biology of sex in marsupials. Aust. J. Sci. 32, 307-314.

Thibault, C. (1973) Sperm transport and storage in vertebrates. J. Reprod. Fert., Suppl. 18, 39-53.

Ullmann, S.L. (1976) Anomalous litters of hybrid mice and the retention of spermatozoa in the female tract. J. Reprod. Fert. 47, 13-18.

Wood, D.H. (1970) An ecological study of Antechinus stuartii (Marsupialia) in a South East Queensland rain forest. Aust. J. Zool. 18, 185-207.

Woolley, P. (1966a) Reproduction in Antechinus spp. and other dasyurid marsupials. Symp. zool. Soc., Lond. 15, 281-294.

Woolley, P. (1966b) Reproductive biology of Antechinus stuartii Macleay (Marsupialia: Dasyuridae). Ph.D. thesis, Australian National University, Canberra.

Woolley, P. (1973) Breeding patterns and the breeding and laboratory maintenance of dasyurid marsupials. Exp. Anim. (Tokyo) 22, Suppl. 161-172.

\section{Received 5 October 1982}

